\title{
Chapter 4 International experience feedback for research reactors
}

The gathering of relevant information about events occurring at research reactors during operation and the analysis of this information, which constitute what is known as experience feedback, are essential to improve the safety of these reactors. Despite the wide variety of different designs and operational conditions of these reactors, the lessons learned from an incident at a research reactor can prevent a similar incident happening again at that reactor or at another reactor. For example, incidents of excessive exposure of operators or experimenters to ionizing radiation, loss of integrity of water tanks or radioactive effluent storage tanks, incidents caused by organizational or human failures, and incidents due to the obsolescence or ageing of equipment, or to insufficient quality of operating procedures can offer lessons that apply to many different types of facility. Following the example of initiatives regarding experience feedback implemented by a number of countries - including France, a topic that will be discussed in more detail in chapter 10 in the second part of this document - the IAEA developed and implemented the Incident Reporting System for Research Reactors (IRSRR), the principles and operation of which are very similar to the system for power reactors (Incident Reporting System, or IRS).

However, although experience with research reactors can be shared very widely at international level using the IRSRR system, not all incidents are fed into it.

Bilateral and multilateral relations have developed between research reactor operators which generally enable more targeted exchanges to take place. For example, every 18 months the International Group on Research Reactors (IGORR) organizes conferences where safety issues related to research reactors are explained and discussed. 
Finally, the concept of experience feedback should be broadened to include the analysis of events affecting other types of facility such as power reactors, from which generic lessons can be learned that are also relevant to research reactors; the example of the Fukushima Daiichi nuclear power plant accident is a good illustration, which will be discussed in more detail later on.

\subsection{The IAEA incident reporting system (IRSRR)}

The IRSRR system was set up by the IAEA in January 2000 and is the only global platform for sharing experience of research reactor operation. The system is used to collect and disseminate technical information about safety-related events (including radiological events) at research reactors, including those that happened before the system was set up. The information contained in the IRSRR database is technical information, unlike the information in the INES ${ }^{79}$ database. The purpose of the INES database is to provide quick general information to the media and the public about events that occur at nuclear facilities, with an assessment of their real or assumed severity (INES classification).

The IRSRR guidelines for use define incident categories, the format and content of the reports to be sent, and a list of identification and incident type codes. This information makes it easier to search for a particular event in the database, which can only be accessed by the countries that contribute to it.

In particular, an incident report must state what happened during the event, and give an analysis of the causes and the lessons learned, and the corrective measures taken to prevent it happening again.

Each of the 54 countries that contribute to the IRSRR system officially appoints a national coordinator, who becomes the contact person for the manager of the system within the IAEA. These coordinators are responsible in particular for submitting reports of incidents that have occurred in their country to the IAEA, and for disseminating information received from the IRSRR system within their country. IRSN has been designated national coordinator for France. The incident reports that it sends to the IAEA are prepared jointly with the operators concerned.

For the IRSRR system to be effective, each contributing country must as quickly as possible send the IAEA reports of incidents at its research reactors that meet the incident reporting criteria defined in the IRSRR guidelines. According to these criteria, relevant incidents are incidents considered to be significant as regards safety, incidents from which lessons can be learned that could be useful for other facilities, and incidents leading to significant radioactive releases or significant exposure of people to ionizing radiation.

Digests are regularly prepared by the IAEA (with contributors from the Member States), and the IAEA also organizes periodic meetings (approximately every two years) of the national coordinators, where the incident reports sent in by the participating

79. International Nuclear Event Scale. 
countries are presented and discussed. An IAEA document ${ }^{80}$ published in 2015 summarises the incidents entered into the IRSRR database up to 2015; it shows that the majority of incidents at research reactors include causes related to organizational or human factors or causes related to the ageing of facilities. A breakdown of the identified causes is given in figure 4.1 below.

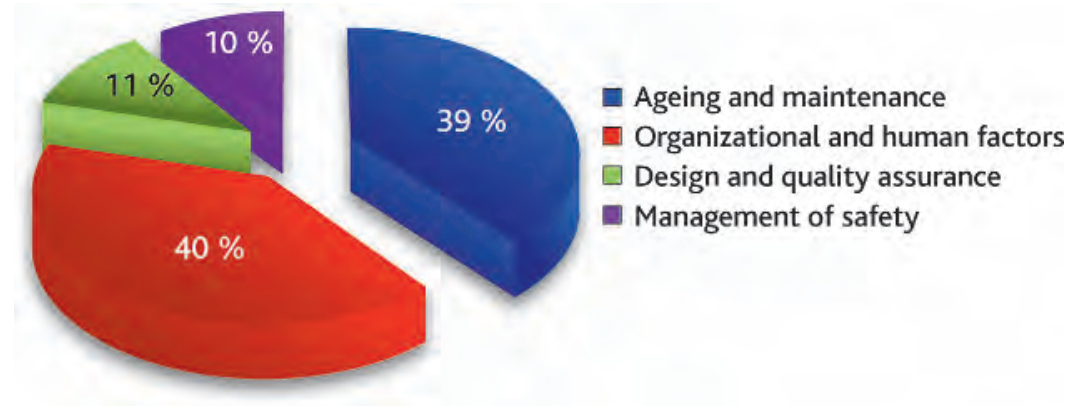

Figure 4.1. Distribution of the identified causes of events entered into the IRSRR database, according to IAEA-TECDOC-1762. (c) Georges Goué/IRSN.

\subsection{Serious incidents and accidents at research reactors}

Modifications (which are quite common) to the configuration of a research reactor core for experimental purposes, the associated handling operations, and the high reactivity "worth" of components of the core, all lead to higher risks of a reactivity accident or an object being dropped on the core or on fuel elements stored nearby than at other types of nuclear facility. In the past, a number of reactivity - or criticality - accidents happened at nuclear facilities (research reactors and other facilities) throughout the world that led to serious irradiation of personnel (operators or experimenters), or even their death; however, the frequency of these accidents has diminished considerably since the early $1970 \mathrm{~s}^{81}$.

A selection of a few serious incidents and accidents at different research reactors ${ }^{82}$ is presented in brief below.

80. IAEA-TECDOC-1762, "Operating Experience from Events Reported to the IAEA Incident Reporting System for Research Reactors", 2015.

81. See the very comprehensive document published by the Los Alamos National Laboratory (run by the University of California on behalf of the US DOE) - entitled "A Review of Criticality Accidents") (reference LA 13638, 2000 revision). From 1945 to the early 1960s, several accidents happened each year at research facilities in the broad sense (reactors and other facilities); there were four in 1968, then two in 1971, one in 1983 and one in 1997.

82. The estimated doses are not always stated in the available sources; for some of these accidents, the values given in different sources are not consistent with one another. 


\section{December 1952 - NRX reactor (42 MW) - Chalk River Laboratories (Ontario, Canada)}

A power excursion at the NRX reactor, a light water-cooled and heavy water-moderated reactor, occurred as a result of failures and human errors, especially the deliberate reduction of the flow of light water for cooling the fuel elements. Because light water acts as a neutron poison, this reduction in flow increased the reactivity and the power of the reactor to around twice the maximum authorised power. The power excursion was stopped by draining the heavy water. The core was destroyed and $3.7 \times 10^{14} \mathrm{~Bq}$ was released into the building basements in around $4,000 \mathrm{~m}^{3}$ of reactor cooling water. 31 people were irradiated at effective doses ranging from $0.04 \mathrm{~Sv}$ to $0.17 \mathrm{~Sv}$. The accident led to a significant transfer of radioactivity into the environment (via the facility's stack).

\section{- 24 May 1958 - NRU reactor (135 MW) - Chalk River Laboratories (Ontario, Canada)}

A fuel element in the NRU heavy water reactor caught fire while it was being unloaded. This element had been damaged the previous day along with other fuel elements during a reactor power increase. This accident caused large-scale contamination of the reactor building and the irradiation of workers.

\section{- 15 October 1958 - (Zero-power) research reactor at the Boris Kidric Institute in Vinca (former Yugoslavia)}

A power excursion occurred in the reactor when the heavy water exceeded the critical level due to incorrect regulation (the chambers used for reactor power measurement were saturated). This accident, which was halted by an operator who ordered the cadmium safety rods to be dropped, did not cause any damage to the reactor core, but six people received significant amounts of radiation: one of them received around 4.3 Sv and died; the other five were treated in France by bone marrow transplant.

\section{- 3 January 1961 - SL-1 reactor $^{83}$ (3 MW) - National Reactor Testing Area, Idaho, USA}

A power excursion occurred during a maintenance operation to prepare the SL-1 reactor to be restarted. The maintenance procedure required the control rods to be withdrawn by a few centimetres to reconnect them to their drive motors. The accident occurred when one of the control rods was withdrawn too quickly and too far from the planned position. The reactor power reached nearly $20 \mathrm{GW}$ in $4 \mathrm{~ms}$ and the resulting energy release caused a pressure wave that pushed the control rods upwards. This accident caused the death of three people (two operators were killed instantly by the explosion following the power excursion and a third died two hours later).

The accident and the lessons learned are described in more detail in chapter 8.

83. Stationary Low Power Reactor Number One. 


\section{December 1965 - VENUS reactor ${ }^{84}(0.5 \mathrm{~kW})$ - Mol (Belgium)}

A limited power excursion occurred as a result of a handling error. The experimental programme on the day of the accident consisted of determining the "efficiency" of the control rods based on the correlation between the displacement of the rods and the displacement of the level of the moderator (a mixture of heavy water and light water), with the reactor in a critical state. The operator made a handling error, withdrawing a control rod before inserting another, despite the fact that the written instructions stated that the other rod should be inserted first. There was no damage to the facility but the operator received a severe dose of radiation (doses received: $5 \mathrm{~Sv}$ in the chest and $40 \mathrm{~Sv}$ on one foot). He was saved but had to have the irradiated foot amputated.

\section{November 1967 - SILOE reactor (15 MW) - Grenoble (France)}

The partial melting of six fuel plates in a "control element ${ }^{85}$ " occurred during a reactor power increase. The incident, attributed to a plate cooling failure, led to the release of around $2 \times 10^{15} \mathrm{~Bq}$ into the pool water and $7.4 \times 10^{13} \mathrm{~Bq}$ through the stack (mainly noble gases). This event is described more fully in chapter 10.

\section{September 1983 - RA-2 critical assembly - Constituyentes (Argentina)}

A power excursion (representing 10 to $15 \mathrm{MJ}$ of thermal energy brought to the fuel in a few milliseconds) was caused by failure to follow the safety instructions when modifying the core configuration of the RA-2 reactor ${ }^{86}$ (the reactor vessel had not been emptied first). The doses received by the operator were around $23 \mathrm{~Gy}$ due to gamma radiation and $1.7 \mathrm{~Gy}$ due to neutrons. The operator died 48 hours after the accident. Two people in the reactor control room were irradiated (receiving doses of around 0.2 Gy due to gamma radiation and 0.15 Gy due to neutrons), along with five others who received total doses of between 40 and $200 \mathrm{mGy}$ and another two who received total doses of around 10 mGy.

\subsection{Complementary safety assessments carried out internationally following the accident at the Fukushima Daiichi nuclear power plant}

Following the accident that occurred on 11 March 2011 at the Fukushima Daiichi nuclear power plant, operated by TEPCO, a number of initiatives were rapidly introduced to enable complementary assessments to be conducted in the light of the events affecting the Fukushima Daiichi plant, based on experience feedback from the accident.

84. Vulcan Experimental Nuclear System.

85. Fuel element containing an absorbing element.

86. Critical assembly similar to EOLE (see section 5.2). 
The European Council meeting on 24 and 25 March 2011 demanded that the various EU Member States conduct these complementary safety assessments, known as "stress tests", on their nuclear power plants. A specification was drawn up for this purpose, based on proposals by WENRA ${ }^{87}$.

Complementary safety assessments were therefore simultaneously carried out in the different EU countries based on similar specifications, and in some cases extended - as was the case in France and Belgium - to other types of nuclear facility or even to other issues ${ }^{88}$. These complementary safety assessments could therefore be conducted not only on nuclear power reactors, but also on research reactors, fuel cycle facilities, etc.

Some of the first lessons learned from the accident at the Fukushima Daiichi nuclear power plant were indeed generic in nature. In particular they concerned the robustness of facilities with respect to the extreme hazards that can affect nuclear facility sites, emergency response, organization and also the role of the safety authorities. Because these issues are also relevant to research reactors and fuel cycle facilities, many countries have included these in their list of facilities to undergo complementary safety assessments, with priorities relevant to the risks they present (inventory of radioactive materials, age, proximity to residential areas, etc.).

The complementary safety assessments carried out in the EU Member States have generally looked at:

- the possibility of extreme hazards occurring that exceed those considered when the facility was designed, leading to station blackout or total loss of cooling, so that additional measures can be identified where necessary to limit the consequences of these accident situations;

- the actual physical conditions of structures, systems and components significant to the safety of each facility and the potential effects of the failure of non-safety class elements on elements significant to safety, should an extreme event occur (hence the need to conduct detailed inspections of the facility);

- the ability of I\&C and facility monitoring equipment to provide appropriate information in the accident situations considered by the complementary safety assessments (extreme hazards, loss of power or cooling).

The key features of the complementary safety assessments carried out on research reactors in France are presented in section 10.2.

Complementary safety assessments have also been carried out or are planned in countries other than the EU Member States, prioritised on the basis of the risks presented by each facility.

In June 2011, the IAEA organized a conference at ministerial level. An action plan was put in place by the IAEA to improve nuclear safety worldwide.

87. Western European Nuclear Regulators Association.

88. Issues concerning the contractors used by operators were therefore addressed in France. 
In this context, in 2011 the IAEA began preparing a procedure for conducting safety reassessments of research reactors, based on the lessons learned from the accident at the Fukushima Daiichi nuclear power plant. The purpose of this procedure, which was the subject of a final report ${ }^{89}$ published in March 2014, was to obtain consistency between the different approaches of different countries, and to form the basis for any reassessments yet to be carried out. Some of the principles expressed in this IAEA report are explained below.

In this report, the IAEA expressly states firstly that, although the inventory of radioactive material, and consequently the potential hazard associated with research reactors worldwide, is much lower than that for nuclear power plants, generally speaking there are aspects that justify safety reassessment in the light of feedback from the accident at the Fukushima Daiichi nuclear power plant: "the majority of research reactors worldwide were designed decades ago, and their design requirements are not fully in conformance with IAEA Safety Standard No. NS-R-4. In addition, many research reactors are located near populated areas, and for some of these the leaktightness of their confinement buildings is inadequate. These issues complicate the management of accidents that result in radioactive releases. In some other cases, the characteristics of the research reactor site and the site area and site vicinity may have changed since the facility was constructed. Not all the above mentioned issues are reflected in the safety analysis for many facilities". Whether a reassessment is required should be decided on the basis of the potential hazard associated with each research reactor.

In terms of feedback from the accident at the Fukushima Daiichi nuclear power plant, the IAEA draws particular attention in this report to the role and responsibilities of the safety authorities, which need to be clearly defined for both normal operating conditions and accident situations. Moreover, the safety authorities must have the necessary expertise to supervise and review the post-Fukushima reassessments to be carried out by operators.

The main objective of the reassessment is "to evaluate the robustness of the existing reactor protection, in terms of design features and procedures, against the impact of extreme events, with an emphasis on fulfilment of the basic safety functions". A reassessment should consist of:

- a review of the design basis of the reactor facility (taking account of the experimental devices and associated equipment), as described in the safety analysis report;

- a study of events that are beyond the design basis of the facility ${ }^{90}$, which can be initiated by extreme initiating events, in order to assess their potential impact on the basic safety functions and the adequacy of existing measures to mitigate the consequences of accidents, in order to identify the safety improvements needed from both a technical and an organizational point of view.

89. IAEA report entitled "Safety Reassessment for Research Reactors in the Light of the Accident at the Fukushima Daiichi Nuclear Power Plant" - Safety Reports Series No. 80 - 2014.

90. Beyond design basis accidents. 
These reassessments must refer to the current status of the facility as built and as operated (maintenance carried out, modifications made, etc.), the most unfavourable permitted operating conditions, including core configurations, and current and planned experimental devices.

Safety reassessments should consider the possibility of the simultaneous occurrence of more than one external hazard, as well as events that could occur as a result of this.

On the basis of these reassessments, additional measures to prevent or mitigate the consequences of accidents should be defined and implemented if necessary.

Reassessment of the site should look at changes in the site characteristics since the facility was built. This includes changes in the distribution of workers on the site and in the surrounding population, changes made to other facilities within the site area, including changes of use, changes in local transportation routes, changes in local land use and changes in hydrology and topography. Accidents that could occur simultaneously at different facilities should be considered.

The potential impact of extreme hazards on access to the reactor site for operating or on-site response personnel, and the availability of off-site response organizations and response personnel, should also be reassessed. In other words, the emergency response measures must be assessed to make sure they are adequate and can be implemented, including if an extreme hazard occurs that affects several facilities simultaneously.

Reassessments also provide an opportunity to verify:

- the existence of an adequate chain of command for response to an emergency and of procedures and means for effective communication during an emergency;

- preparedness of the on-site response teams and off-site response organizations to manage effectively an emergency affecting several facilities on a single site simultaneously;

- the availability of emergency equipment and the performance of periodic checks on that equipment;

- site accessibility for off-site response teams and the availability of the necessary logistical support.

At a conference held by the IAEA in November 2015, various research reactor operators (e.g. the operators of the IRR1 reactor ${ }^{91}$ in Israel and the SAFARI- 1 reactor in South Africa) presented the actions plans that they had proposed to their respective safety regulators following the safety reassessments conducted on the basis of the IAEA's report mentioned above or the recommendations of ENSREG (European Nuclear Safety Regulators Group ${ }^{92}$ ) in the case of the stress tests.

Generally speaking, and by way of illustration, through the installation of new equipment that can withstand earthquakes associated with the sites, including safety margins, or through the modification of existing equipment to improve this earthquake

91. Israel Research Reactor-1.

92. A European Commission consultative group of independent experts. 
resistance, the reassessments have resulted in proposals to improve the safety of reactors such as:

- seismic detection linked to the reactor protection system, causing an automatic reactor scram in the event of an earthquake;

- an extra system to shut down the chain reaction (injection of a soluble neutron poison, etc.);

- an emergency power supply in addition to the existing power supplies (mobile generator or backup battery), addition of easily accessible external connections;

- additional means of emergency cooling, fire service connections, core spray systems;

- strengthening of the containment vessel to improve its resistance to external natural hazards;

- improvements to emergency ventilation systems and their filtration systems;

- reinforcement of the means provided for effective emergency response, creation of off-site emergency control rooms with feedback of the information necessary to monitor the facility, etc.

Most of these measures had already been implemented at research reactors in France, at the time of safety reviews, or had been reinforced or supplemented during the stress tests carried out following the accident at the Fukushima Daiichi nuclear power plant (this is discussed in section 10.2).

Other proposed improvements resulting from the reassessments concern the safety culture, organizational aspects, and training and qualification programmes of operating personnel.

Schedules have been drawn up for the implementation of these proposed improvements.

In conclusion, the complementary safety assessments performed on research reactors on the basis of feedback from the accident at the Fukushima Daiichi nuclear power plant will help to improve defence in depth, including as regards emergency response. Peer review of the results of this work has been conducted under the auspices of the IAEA, at various technical meetings. 
